Vol. 2, No. 1, Juni 2017, pISSN 2527-2853, eISSN 2549-2985

\title{
Desain Toilet dan Tempat Wudhu Masjid
}

\author{
Budiono $^{1}$, Lea Kristina Anggraeni² \\ 1,2 Jurusan Desain Interior, FTSP ITS, Surabaya \\ 1budiono@interior.its.ac.id, ${ }^{2}$ leaanggraeni@yahoo.com
}

\begin{abstract}
ABSTRAK
Desain toilet dan ruang wudhu di fasilitas publik seperti di kantor, pertokoan, sarana hiburanrekreasi, hotel, restaurant dan bangunan masjid, sebagian besar belum mengakomodasi kebutuhan 'bebas najis' dan privasi aurat penggunanya serta belum memperhatikan lay out toilet, sehingga posisi kloset dan urinal tidak menghadap / membelakangi arah kiblat. Berdasarkan permasalahan tersebut, maka perlu disusun konsep desain dan alternative desain toilet dan tempat wudhu yang lebih Islami. Untuk mewujudkan interior toilet yang Islami tersebut khususnya pada bangunan masjid, maka perlu dilakukan kegiatan penyusunan konsepsi desain toilet dan ruang wudhu yang Islami. Konsep desain ini diperlukan untuk meningkatkan wawasan takmir masjid terhadap persoalan dan solusi fisik dari desain toilet dan ruang wudhu, serta menghasilkan satu alternatif desain sebagai acuan atau langsung dikonstruksi pada kegiatan pembangunan baru atau renovasi.

Konsep desain toilet dan ruang wudhu yang Islami terutama adalah ide tentang bagaimana mendesain urinoir yang dapat menghindari terjadinya percikan balik/cipratan urin (najis) sehingga tidak mengenai tubuh atau pakaian pengguna, serta bagaimana cara meningkatkan privasi visual (aurat) pengguna saat buang air, dan bagaimana menata lay out toilet dan ruang wudhu sehingga tidak menghadap atau membelakangi kiblat. Konsep tersebut diimplementasikan dalam bentuk alternatif desain beruba gambar pradesain.

Dengan adanya konsep desain dan alternatif desain yang Islami diharapkan masyarakat Muslim sebagai penduduk mayoritas di negeri ini tidak gamang dan ragu lagi untuk menggunakan, yang pada gilirannya akan meningkatkan pelayanan masjid pada para jamaahnya karena jamaah akan semakin merasa aman dan nyaman. Yang dijadikan kasus pada studi ini adalah toilet dan ruang wudhu masjid Al-Falah dan Masjid Ampel Surabaya.
\end{abstract}

Kata kunci : aurat; Islami; kiblat; najis; toilet; wudhu

\section{ABSTRACT}

The design of toilets and ablution room in public facilities such as in offices, shops, entertainmentrecreation facilities, hotels, restaurants and especially mosque buildings have not yet accommodated the needs of 'free of unclean' and aurat privacy and also have not yet paid attention to lay out toilets, so the position of the toilet and the urinoir avoiding facing / backing towards Qibla. Based on this, it is necessary to prepare the Islamic design concept of toilet and ablution room. This design concept is needed to improve the insight of 'the mosque's takmir' on the issues and physical solutions of toilet design and ablution room, and to produce an alternative design as a reference to new building construction or renovation activities.

The Islamic design concept of toilet and ablution room is primarily an idea of how to avoid splashes of urine so that it does not affect the body or clothing of the user, and how to better maintain the user's visual privacy while urinating, and not facing or back to Qibla. This concept is implemented in an alternative design in the form of pre-design drawings.

With the Islamic design concept and alternative design, it is expected that the Muslim community as a majority citizen in this country will not be hesitant to use, which in turn will improve the mosque's service to its congregation because the congregation will feel more secure and comfortable. The case in this study is the toilet and ablution room of Al-Falah Mosque and Ampel Mosque in Surabaya.

Keyword: ablution; aurat; Islami; Qibla; toilet; unclean. 


\section{PENDAHULUAN}

\section{A. Latar Belakang}

Sebagai fasilitas umat Islam masjid mempunyai fungsi sebagai pusat ibadah dan pusat kegiatan sosial umat serta sebagai sarana representasi budaya dan peradaban Islam. Sebagai pusat ibadah khususnya sholat, maka masjid terkait dengan permasalahan syarat sahnya sholat antara lain berwudhu dan suci dari najis sehingga diperlukan jaminan sahnya wudhu para jamaah serta kesucian masjid. Sebagai pusat kegiatan umat masjid harus mampu menampung jamaah dengan jumlah tertentu dan kegiatan yang beragam sehingga membutuhkan kapasitas yang cukup dan kualitas pelayanan yang baik. Sebagai sarana untuk representasi budaya dan peradaban Islam maka desain masjid terkait dengan citranya yang selalu bersih, suci, melayani dan estetik. Terkait dengan perihal tersebut, maka ruang-ruang dalam masjid yang perlu mendapat perhatian khusus dalam desainnya antara lain adalah ruang toilet dan ruang wudhu.

Setidaknya ada tiga hal penting dalam penelusuran kebutuhan Muslim di toilet yaitu najis, aurat, dan orientasi non-Kiblat. Najis menurut syariat Islam adalah sesuatu yang dianggap menjijikkan dan menghalangi keabsahan ibadah sholat (Shobirin, 2014). Suci atau terbebasnya badan/tubuh, pakaian dan tempat sholat dari najis merupakan salah satu syarat sahnya sholat. Najis dalam toilet terutama adalah najis karena urine dan tinja. Adapun aurat adalah bagian tubuh manusia yang tidak boleh terlihat oleh orang lain. Aktivitas orang di ruang toilet berpeluang dapat terbuka atau terlihatnya aurat, sehingga privasi terhadap aurat ini menjadi satu permasalahan dalam desain toilet termasuk desain urinoirnya. Tuntunan Islam tentang adab buang air mengharuskan dihindarinya menghadap atau membelakangi arah kiblat pada saat buang air, sehingga perlu optimalisasi desain layout ruang toilet. Kebutuhan seorang Muslim di ruang wudhu agar lebih terjamin keabsahan wudhunya juga terkait dengan menjaga agar najis tidak terkena pada badan dan pakaian.

Dengan adanya interior toilet dan ruang wudhu yang mampu menghindarkan penggunanya dari najis yang terkena tubuh ataupun pakaian, dan yang menawarkan privasi aurat yang lebih tinggi, serta mampu menghindari orientasi kiblat saat buang air, maka pengguna toilet dan tempat wudhu akan merasa lebih aman dan nyaman dalam menjalankan syariat agamanya terutama ibadah sholat. Bila kondisi tersebut tercapai maka dapat dimaknai bahwa keberadaan toilet dan tempat wudhu yang Islami tersebut akan membantu meningkatkan kualitas ibadah sholat kaum Muslimin yang sekaligus juga meningkatkan pelayanan masjid pada para jamaahnya.

Studi tentang konsepsi desain urinoir yang Islami hasil kegiatan sebelumnya dijadikan salah satu rujukan untuk menyusun konsep desain toilet dan ruang wudhu yang Islami. Rumusan konsepsi desain yang Islami tersebut dipakai sebagai bahan kegiatan diskusi dengan para takmir dari 2 (dua) masjid besar di Surabaya yaitu Masjid Al-Falah dan Masjid Ampel. Dengan tambahan hasil diskusi selanjutnya dibuat alternatif desain ruang toilet dan wudhu dari kedua masjid tersebut yang diharapkan dapat digunakan sebagai salah satu acuan dalam kegiatan pembangunan dan pengelolaan fisik masjid khususnya toilet dan ruang wudhu. 


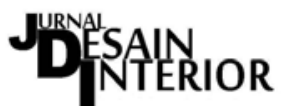

Vol. 2, No. 1, Juni 2017, pISSN 2527-2853, eISSN 2549-2985

\section{B. Persoalan Prioritas}

Persoalan prioritas yang direncanakan akan diselesaikan dalam kegiatan desain toilet dan ruang wudhu masjid ini adalah :

1. Terbebasnya tubuh dan pakaian jamaah dari najis saat buang air dan berwudhu demi sahnya sholat seseorang. Najis dalam pandangan syariat Islam yaitu benda yang kotor yang mencegah sahnya suatu ibadah yang menuntut seseorang dalam keadaan suci seperti sholat dan thowaf. Dalam Al-Qur'an perkataan najis disebut juga dengan 'rijsun' seperti tercantum dalam surat Al-Maidah ayat 90. Najis berbeda dengan kotor, benda yang kelihatan kotor belum tentu najis, begitu juga sebaliknya. Kotoran manusia baik yang keluar dari dubur atau qubul hukumnya najis, kecuali air sperma.

2. Aktifitas buang air sangat memberikan peluang terlihatnya aurat oleh orang lain, sehingga tuntunan tentang menjaga privasi aurat saat buang air ini perlu ditelaah dan diterapkan. Penghalang yang paling sering digunakan Rasulullah ketika buang hajat adalah dinding atau pagar kebun kurma (yakni dibalik tanah tinggi atau dinding kebun kurma). (Hadits Riwayat Muslim).

3. Sebagian ulama berpendapat bahwa diharamkan buang air sambil menghadap atau membelakangi kiblat, baik dilakukan di dalam ruangan (WC) ataupun di luar ruangan/bangunan. Sebagian ulama yang lain berpendapat bahwa diharamkan menghadap atau membelakangi kiblat ketika buang hajat di ruang terbuka dan dibolehkan ketika berada di ruangan tertutup (WC). Permasalahannya adalah bagaimana layout ruang dan sanitair sehingga ketika jamaah buang air akan terhindar dari posisi menghadap atau membelakangi kiblat.

4. Air musta'mal adalah air dengan volume tertentu yang sudah pernah digunakan untuk bersuci termasuk berwudhu yang menurut hukum fiqih tidak sah digunakan lagi untuk berwudhu. Desain tempat wudhu disyaratkan menghindari terjadinya penggunaan air musta'mal tersebut.

Sebagai implementasi dari konsepsi di atas, maka diperlukan satu alternatif desain toilet dan ruang wudhu yang lebih Islami serta mengacu pada kondisi eksisting saat ini. Alternatif desain ini oleh pihak takmir masjid akan dipakai sebagai salah satu acuan desain atau bahkan akan langsung diterapkan dalam kegiatan renovasi pembangunan pada waktu yang akan datang.

\section{Tujuan}

Tujuan dari desain ini adalah :

1. Menyusun Konsep Desain Toilet dan Ruang Wudhu yang Islami.

Konsep desain dimaksudkan sebagai gagasan-gagasan dalam menjawab permasalahan toilet dan ruang wudhu yang ada saat ini terkait dengan tuntunan syariat Islam yang mengharuskan terbebasnya tubuh dan pakaian dari najis demi shahnya sholat seseorang, tentang privasi aurat dan orientasi non-kiblat, serta tentang menghindari air musta'mal. Selain tuntutan syariah juga aspek desain pada umumnya terutama ergonomi untuk keamanan dan kenyamanan pengguna.

2. Membuat Alternatif Desain Urinoir dan Layout Toilet yang Islami.

Konsep desain tersebut di atas diimplementasikan dalam desain toilet dan ruang wudhu yang Islami. Desain berupa satu alternatif desain yang optimal dalam menerapkan konsep desain di atas. Desain ini berupa gambar prarencana 2D, serta gambar perspektif 3D. 


\section{DASAR TEORI}

Landasan utama dari desain ruang toilet dan ruang wudhu yang bersendikan syariat Islam adalah perihal najis, aurat, orientasi non-kiblat, dan posisi berdiri saat buang air kecil selain aspek ergonomi dalam desain.

\section{Najis}

\begin{tabular}{|c|c|c|}
\hline $\begin{array}{l}\text { Dalil Al-qur'an / } \\
\text { Hadits }\end{array}$ & $\begin{array}{l}\text { Tafsir dalam Konteks } \\
\text { Arsitektur }\end{array}$ & $\begin{array}{l}\text { Contoh Konsekuensi } \\
\text { Arsitektural }\end{array}$ \\
\hline 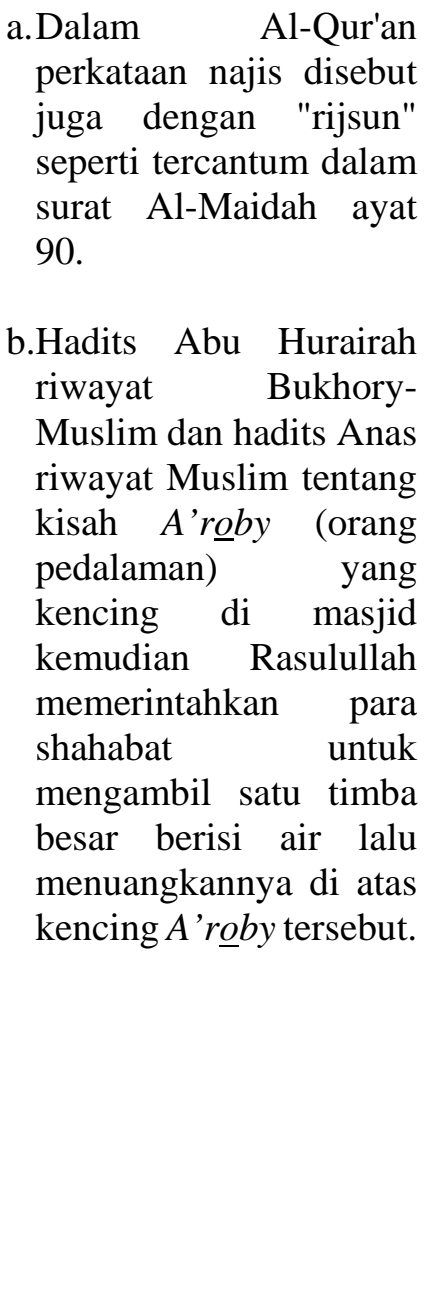 & $\begin{array}{l}\text { a. Najis dalam pandangan } \\
\text { syariat Islam yaitu benda } \\
\text { yang kotor yang } \\
\text { mencegah sahnya suatu } \\
\text { ibadah yang menuntut } \\
\text { seseorang dalam keadaan } \\
\text { suci seperti sholat dan } \\
\text { thowaf. } \\
\text { b. Najis berbeda dengan } \\
\text { kotor, benda yang } \\
\text { kelihatan kotor belum } \\
\text { tentu najis, begitu juga } \\
\text { sebaliknya. Kotoran } \\
\text { manusia baik yang keluar } \\
\text { dari dubur atau qubul } \\
\text { hukumnya najis, kecuali } \\
\text { air sperma. } \\
\text { c. Sisi pendalilan dari hadits } \\
\text { ini adalah bahwa } \\
\text { Rasulullah supaya } \\
\text { memerintahkan su at an } \\
\text { menuangkan air di atas } \\
\text { kencing tersebut untuk } \\
\text { mensucikan sehingga } \\
\text { menunjukkan bahwa } \\
\text { kencing manusia adalah } \\
\text { najis. }\end{array}$ & $\begin{array}{l}\text { a.Terjadinya Percikan balik } \\
\text { urin: } \\
\text { 1) Ketika Buang Air } \\
\text { 2) Ketika Bersuci } \\
\text { b.Peluang terkena urin : } \\
\text { 1) Pada badan } \\
\text { 2) Pada pakaian } \\
\text { 3) Pada lantai ruang toilet }\end{array}$ \\
\hline
\end{tabular}


2. Aurat

\begin{tabular}{|c|c|c|}
\hline Dalil Al-qur'an / Hadits & $\begin{array}{c}\text { Tafsir dalam Konteks } \\
\text { Arsitektur }\end{array}$ & $\begin{array}{c}\text { Contoh Konsekuensi } \\
\text { Arsitektural }\end{array}$ \\
\hline $\begin{array}{l}\text { a. Riwayat Mughirah bin } \\
\text { Syu'bah Radhiyallahu } \\
\text { 'Anhu ia berkata: "Ketika } \\
\text { saya menyertai } \\
\text { Rasulullah Shallallahu } \\
\text { 'Alaihi wa Sallam dalam } \\
\text { sebuah lawatan, beliau } \\
\text { terdesak buang hajat. } \\
\text { Beliaupun menjauh dari } \\
\text { tepi jalan." (H.R. At- } \\
\text { Tirmidzi, ia berkata: } \\
\text { Hadits ini hasan shahih). } \\
\text { a.Abdurrahman bin Abi } \\
\text { Quraad meriwayatkan: } \\
\text { "Saya pernah menyertai } \\
\text { Rasulullah ke sebuah } \\
\text { padang luas. Jika beliau } \\
\text { hendak buang hajat maka } \\
\text { beliau akan pergi } \\
\text { menjauh." (H.R. An- } \\
\text { Nasa'i dan dicantumkan } \\
\text { dalam Shahih Al-Jami'). } \\
\text { Penghalang yang paling } \\
\text { sering digunakan } \\
\text { Rasulullah ketika buang } \\
\text { hajat adalah dinding atau } \\
\text { pagar kebun kurma (yakni } \\
\text { dibalik tanah tinggi atau } \\
\text { dinding kebun kurma). } \\
\text { (Hadits Riwayat Muslim). }\end{array}$ & $\begin{array}{l}\text { Fasilitas buang air kecil } \\
\text { perlu dilengkapi } \\
\text { dengan elemen } \\
\text { pembatas/ penghalang } \\
\text { visual agar aurat tidak } \\
\text { terlihat orang lain yang } \\
\text { dilarang oleh agama. }\end{array}$ & $\begin{array}{c}\text { Gambar 4. Tipe sekat ruang penuh di } \\
\text { toilet Masjidil Haram } \\
\text { Sumber: } \\
\text { https://shafamarwah.worldpress.com, } \\
\text { (2016) }\end{array}$ \\
\hline
\end{tabular}




\section{Menghadap atau Membelakangi Kiblat}

\begin{tabular}{|c|c|c|}
\hline Dalil Al-Qur’an / Hadits & $\begin{array}{c}\text { Tafsir dalam Konteks } \\
\text { arsitektur }\end{array}$ & $\begin{array}{c}\text { Contoh Konsekuensi } \\
\text { Arsitektural }\end{array}$ \\
\hline 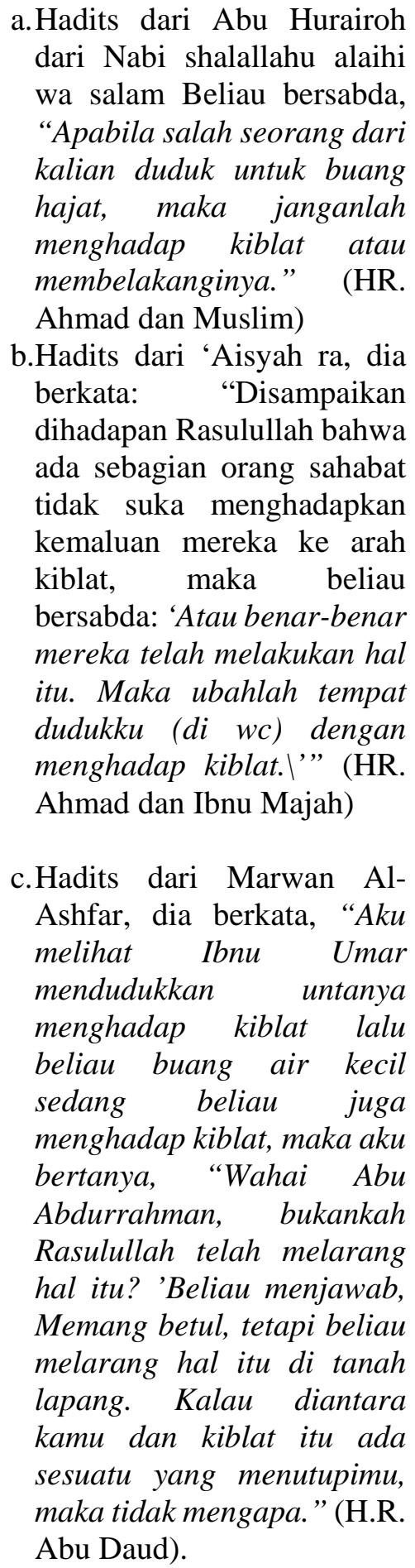 & $\begin{array}{l}\text { a. Sebagian ulama } \\
\text { berpendapat bahwa } \\
\text { diharamkan buang air } \\
\text { sambil menghadap atau } \\
\text { membelakangi kiblat, } \\
\text { baik dilakukan di dalam } \\
\text { ruangan (wc) ataupun di } \\
\text { luar ruangan/ bangunan. } \\
\text { b. Sebagian ulama yang } \\
\text { lain berpendapat bahwa } \\
\text { diharamkan menghadap } \\
\text { atau membelakangi } \\
\text { kiblat ketika buang } \\
\text { hajat di ruang terbuka } \\
\text { dan dibolehkan ketika } \\
\text { berada di ruangan } \\
\text { tertutup (wc). }\end{array}$ & $\begin{array}{l}\text { Gambar 5. Alternatif lay out } \\
\text { ruang buang hajat (WC) yang } \\
\text { tidak menghadap/membelakangi } \\
\text { kiblat. } \\
\text { Sumber: Dokumentasi } \\
\text { Penulis (2016) }\end{array}$ \\
\hline
\end{tabular}




\section{Di|Fink}

Vol. 2, No. 1, Juni 2017, pISSN 2527-2853, eISSN 2549-2985

\section{Posisi Berdiri Saat Buang Air Kecil}

a. Dari Hudhaifah r.a. bahwa (tatkala) Nabi SAW di tempat pembuangan sampah suatu kaum, beliau kencing dengan berdiri, kemudian aku hendak menghindar darinya, lalu Rasulullah bersabda (kepadaku), "Mendekatlah kesini!" Kemudian aku mendekat sampai aku berdiri di belakangnya, lalu beliau berwudhu' dan mengusap bagian khufnya." (H.R Muslim).

b. Aisyah r.a. menegaskan, "Barangsiapa yang menyampaikan kepada kamu sekalian bahwa Rasulullah SAW (pernah) kencing berdiri, maka janganlah kamu percaya kepadanya: Rasulullah tidak pernah kencing, kecuali dalam keadaan duduk." (Shahih: Shahih Nasa'I \& Tirmidzi dengan lafadz "ILLAA QAA'IDAN").

c. Pernyataan Aisyah r.a. ini tidak menafikan riwayat dari Huzhaifah karena Aisyah r.a. menginformasikan apa yang ia lihat, sedangkan Huzhaifah menyampaikan apa yang dia lihat juga. Dan sudah dimaklumi bahwa sebuah kabar yang menetapkan sesuatu harus diutamakan (didahulukan) daripada yang menafikan, karena yang menetapkan memiliki pengetahuan yang lebih daripada yang menafikan.

d. Dari Hadits di atas dapat disimpulkan bahwa buang air kecil (kencing) sambil berdiri diperbolehkan oleh agama, sekalipun ada pendapat lain yang menyatakan bahwa dengan posisi jongkok lebih baik/afdhol dibanding dengan posisi berdiri.

\section{PEMBAHASAN}

\section{A. Masalah Desain}

Dari hasil studi pengguna, eksisting, ergonomi dan studi fiqih Islam, maka dapat dirumuskan beberapa masalah desain toilet dan ruang wudhu sebagai berikut:

1. Diidentifikasi terjadinya percikan balik (splash back) atau cipratan urine pada saat buang air kecil serta pada saat bersuci, sehingga masalahnya adalah bagaimana desain urinoir agar percikan balik tersebut tidak sampai mengenai tubuh serta pakaian pengguna urinoir.

2. Setelah proses bersuci (membersihkan alat vital) pada umumnya pengguna langsung membetulkan posisi celananya dan kemudian mencuci tangannya di wastafel sebelum meninggalkan ruang toilet. Hal ini menimbulkan kesangsian akan kesucian tangan (terutama tangan kiri). Bila tangan tersebut masih najis maka dengan sendirinya akan mengena pada pakaian/celana, sehingga masalahnya adalah bagaimana desain urinoir agar ketika membetulkan/menutup celana tersebut kondisi kedua tangan sudah suci.

3. Selama pengguna urinoir melakukan kegiatan buang air kecil, diidentifikasi adanya kekhawatiran terlihatnya aurat oleh orang lain, sehingga masalahnya adalah bagaimana desain urinoir sehingga privasi visual terhadap aurat ini bisa lebih ditingkatkan.

4. Kondisi ruang toilet pada bangunan sangatlah beragam baik dari segi akses keluarmasuknya, bentuk dan ukuran ruangnya, sehingga dengan adanya tuntutan agar ketika melakukan aktivitas buang air tidak menghadap atau membelakangi arah Kiblat diperlukan optimalisasi desain urinoir serta desain layout ruang toilet yang mampu memenuhi kebutuhan tersebut.

5. Setelah buang air kecil, pengguna urinoir yang ada saat ini akan membersihkan dinding dalam urinoir yang terkena urin dengan air bersih langsung dari PDAM, sedangkan dalam 
aktivitas buang air kecil terdapat air limbah dari aktivitas memcuci tangan yang dimungkinkan untuk dimanfaatkan membersihkan dinding dalam urinoir tanpa harus menggunakan air bersih langsung dari PDAM sehingga lebih efisien dalam penggunaan air. Bagaimana desain urinoir yang mampu menjawab permasalahan tersebut.

6. Bagaimana menghindari terjadinya 'air musta'mal' (air yang telah digunakan untuk berwudhu) untuk kegiatan berwudhu lagi.

7. Bagaimana agar ketika berwudhu dan setelah berwudhu jamaah merasa aman dari kemungkinan terjatuh karena licin atau ketidakseimbangan tubuh.

\section{B. Konsep Desain}

Dari masalah desain tersebut di atas dapat dirumuskan beberapa kriteria desain atau konsep desain sebagai gagasan solusi terhadap permasalahan desain toilet dan ruang wudhu sebagai berikut:

1. Konsep Desain Toilet

a) Menghindari cipratan/percikan balik urin pada badan dan pakaian pengguna saat buang air maupun saat bersuci setelah buang air dengan cara membuat cerung bidang dalam urinoir cukup dalam (jarak antara bibir urinoir terbawah dengan lubang afvour cukup tinggi)

b) Menghindari tertempelnya urin pada pakaian saat menutup kembali pakaian (celana dan celana dalam) setelah buang air kecil dengan cara mengintegrasikan fungsi wastafel ke desain urinoir untuk kegiatan bersuci alat vital setelah buang air dan membersihkan tangan setelah bersuci; sehingga pengguna akan dapat membersihkan tangan sebelum menutup kembali pakaian (ketika menutup kembali pakaian kondisi tangan sudah bersih dari najis).

c) Menghindari terlihatnya aurat pengguna saat buang air kecil dengan cara memposisikan bidang penghalang visual (sekat) lebih dekat dengan badan pengguna sehingga celah antara sekat dengan badan pengguna dibuat seminimal mungkin namun tetap menyediakan ruang manuver tangan selama proses buang air.

d) Menghemat penggunaan air sebagai pembersih dinding dalam urinoir dengan cara tidak menggunakan air bersih langsung dari kran air untuk membersihkan dinding dalam urinoir, tetapi menggunakan air limbah dari kegiatan membersihkan farji dan tangan setelah buang air kecil.

e) Hubungan lantai toilet dengan lantai ruang wudhu atau lantai dalam masjid ditempatkan ‘bak control kesucian’ untuk memastikan kesucian kaki

2. Konsep Desain Ruang Wudhu

a) Ketinggian kran wudhu sedemikian rupa sehingga air bekas basuhan muka (musta'mal) tidak menetes ke telapak tangan saat wudhu.

b) Pegangan tangan (handle) untuk tipe wudhu posisi berdiri dan duduk, dan injakan kaki untuk tipe wudhu berdiri untuk keamanan dan kenyamanan saat dan setelah berwudhu.

c) Lantai daerah basah (sekitar jatuhnya air kran) diberi kemiringan dan bertekstur kasar. Sedangkan lantai 'sirkulasi' diberi material penutup lantai sehingga air di telapak kaki bisa berkurang serta tidak licin.

d) Hubungan lantai tempat wudhu dengan lantai ruang toilet atau lantai luar masjid ditempatkan ‘bak kontrol kesucian’ untuk memastikan kesucian kaki. 


\section{Desain}

Konsep desain tersebut di atas dapat diimplementasikan kedalam desain toilet dan ruang wudhu dengan mengambil kasus Masjid Al-Falah dan Masjid Ampel di Surabaya.

1. Toilet dan Ruang Wudhu Masjid Al-Falah.

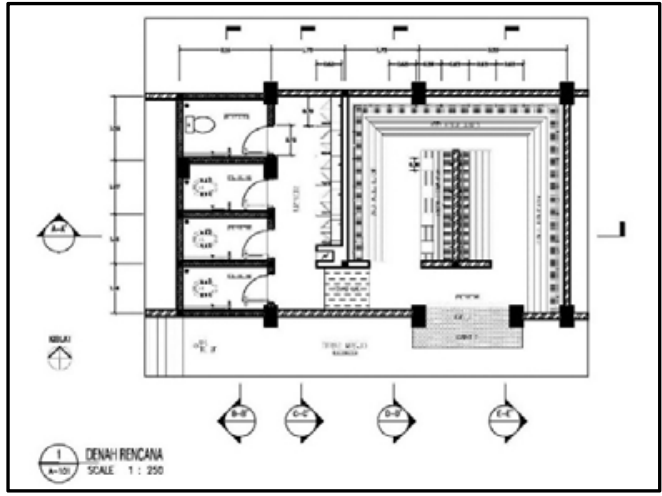

Gambar 6. Denah Toilet dan Ruang Wudhu Masjid Al-Falah.

Sumber: Dokumentasi Penulis (2016)

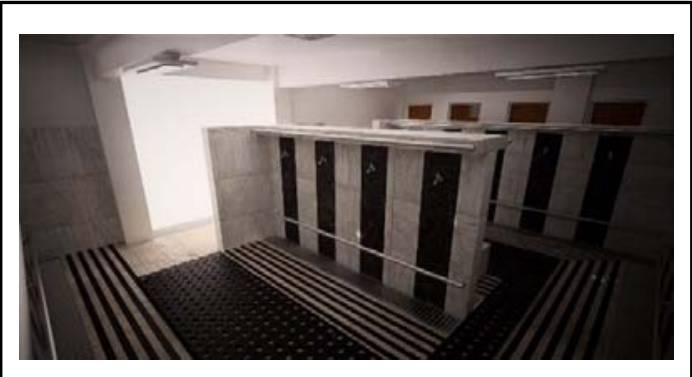

Gambar 8. Perspektif-2 R. Wudhu Masjid Al-Falah. Sumber: Dokumentasi Penulis (2016)

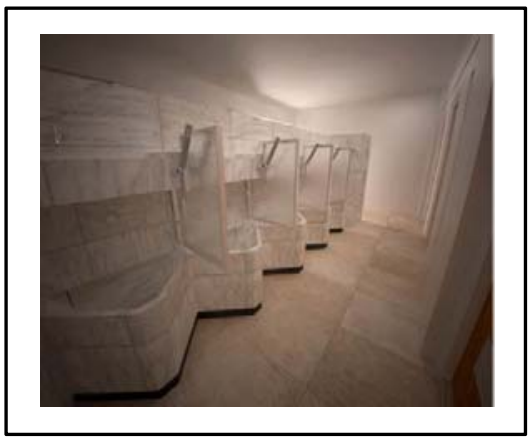

Gambar 10. Perspektif-1 Ruang Toilet Masjid Al-Falah. Sumber: Dokumentasi Penulis (2016)

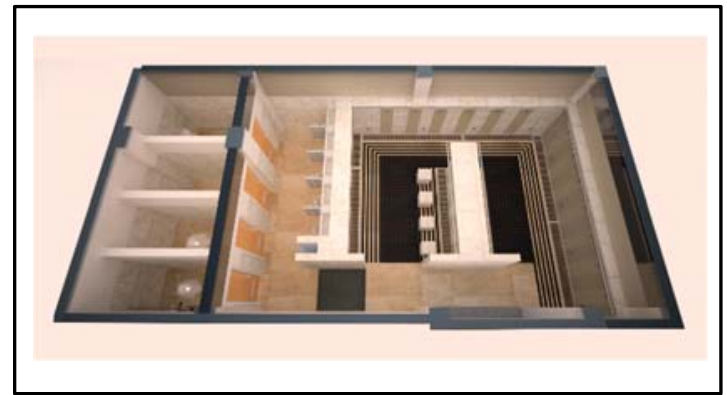

Gambar 7. Perspektif-1 Toilet dan Ruang Wudhu Masjid Al-Falah.

Sumber: Dokumentasi Penulis (2016)

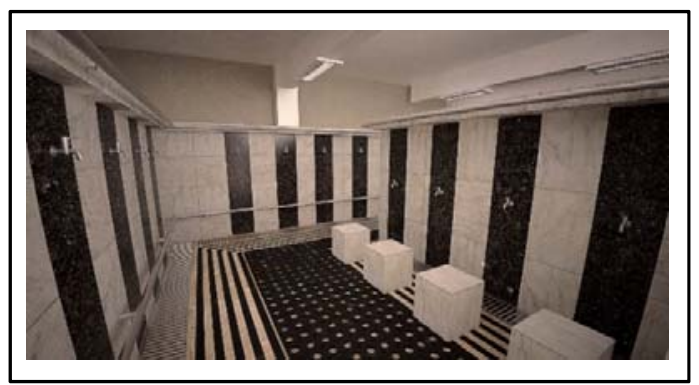

Gambar 9. Perspektif-3 R. Wudhu Masjid AlFalah.

Sumber: Dokumentasi Penulis (2016)

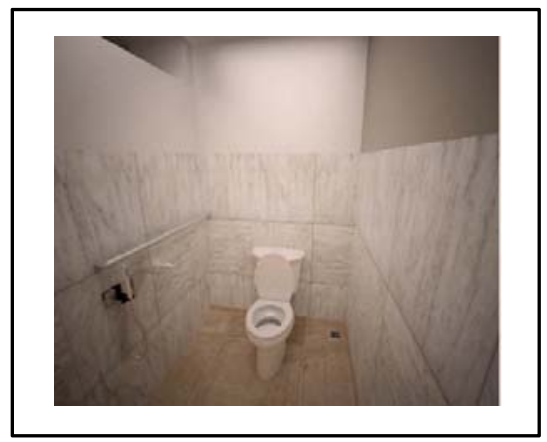

Gambar 11. Perspektif-2 Toilet Masjid Al-Falah Sumber: Dokumentasi Penulis (2016) 
2. Toilet dan Ruang Wudhu Masjid Ampel.

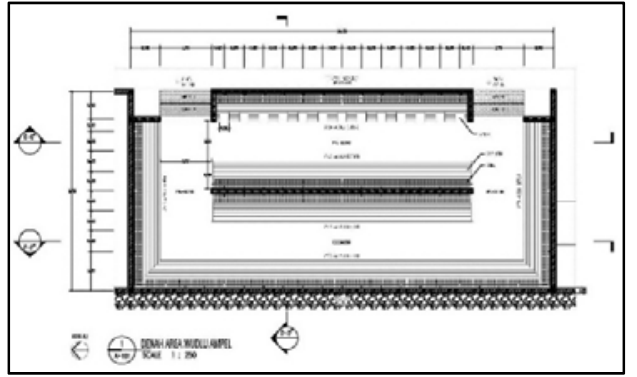

Gambar 12. Denah Ruang Wudhu Masjid Ampel. Sumber: Dokumentasi Penulis (2016)

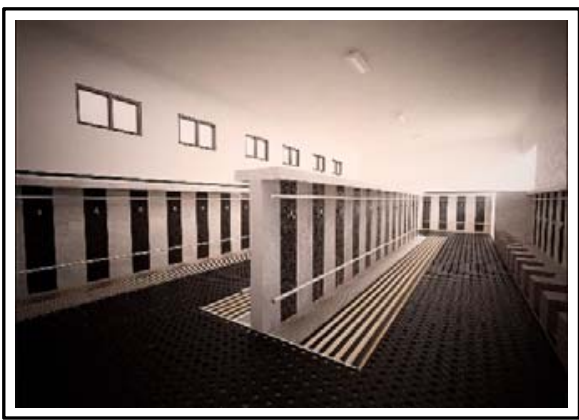

Gambar 14. Perspektif-2 Ruang Wudhu Masjid Ampel.

Sumber: Dokumentasi Penulis (2016)

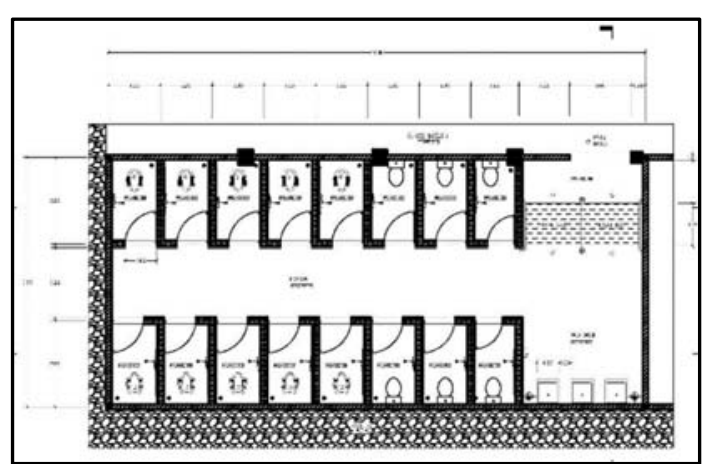

Gambar 16. Denah Ruang Toilet Masjid Ampel. Sumber: Dokumentasi Penulis (2016)

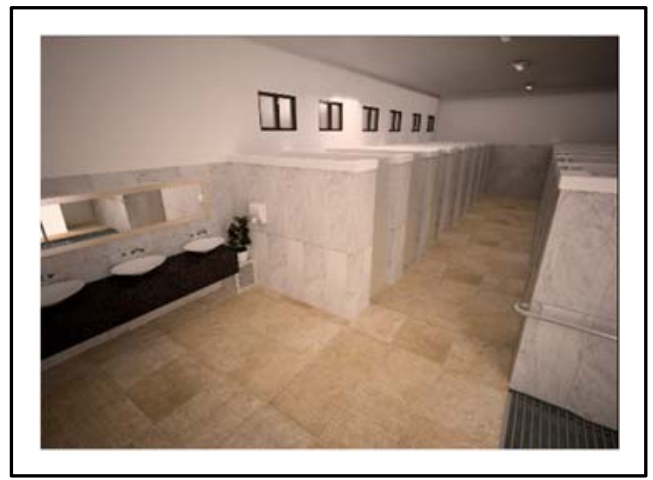

Gambar 18. Perspektif-2 Ruang Toilet Masjid Ampel. Sumber: Dokumentasi Penulis (2016)

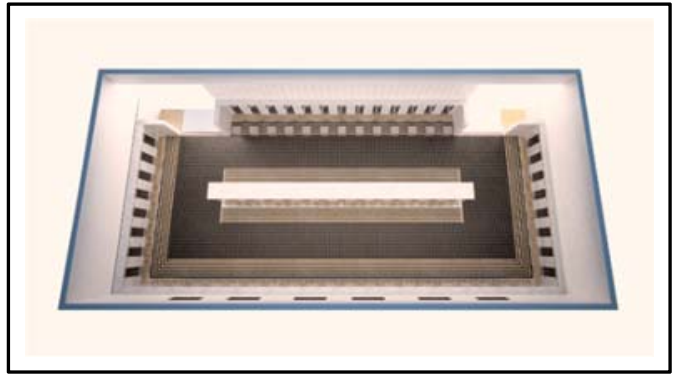

Gambar 13. Perspektif-1 R. Wudhu Masjid Ampel. Sumber: Dokumentasi Penulis (2016)

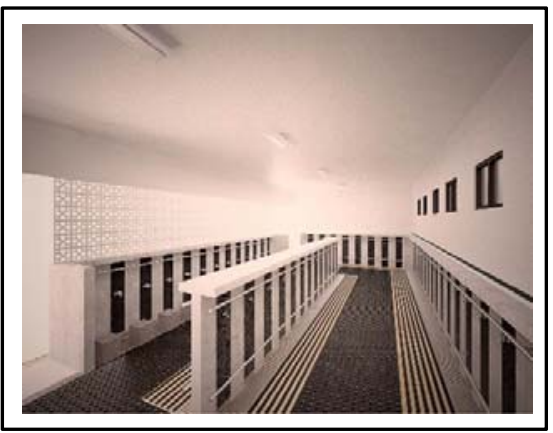

Gambar 15. Perspektif-3 R.Wudhu Masjid Ampel. Sumber: Dokumentasi Penulis (2016)

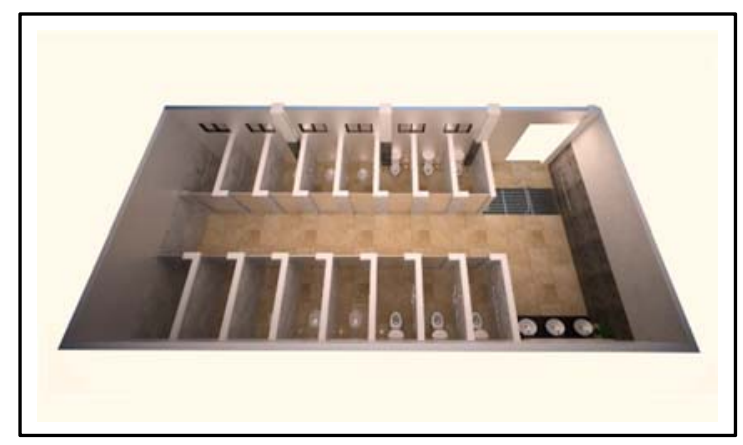

Gambar 17. Perspektif-1 Toilet Masjid Ampel. Sumber: Dokumentasi Penulis (2016)

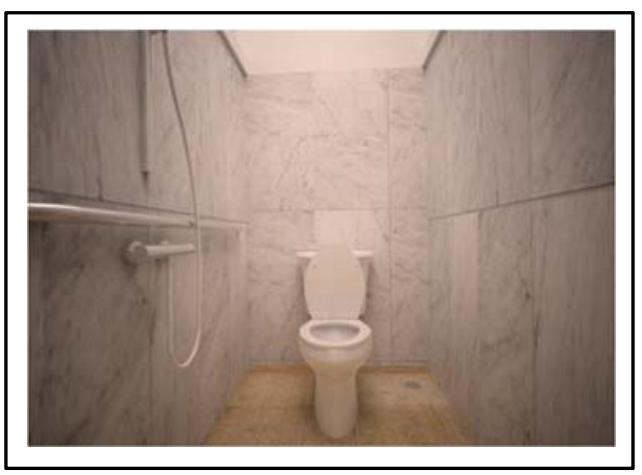

Gambar 19. Perspektif-3 Toilet Masjid Ampel. Sumber: Dokumentasi Penulis (2016) 


\section{KESIMPULAN DAN SARAN}

Dari hasil desain ini dapat ditarik kesimpulan sebagai berikut:

1. Konsep desain toilet dan ruang wudhu yang berbasis syariah mampu disusun guna memenuhi tuntutan desain yang lebih menjamin keamanan dan kenyamanan ibadah jamaah masjid.

2. Alternatif desain toilet dan ruang wudhu yang menerapkan konsep desain yang Islami mampu dibuat guna masukan dan acuan dalam kegiatan perencanaan dan pengelolaan fasilitas masjid yang lebih tanggap terhadap tuntutan syar'i.

3. Konsep desain dan alternatif desain toilet dan ruang wudhu ini dapat dipakai juga untuk kajian lebih lanjut tentang fasilitas lain di luar masjid khususnya bagi umat Islam yang selalu memperhitungkan tuntunan syariah selain tuntutan aspek desain lainnya.

\section{DAFTAR PUSTAKA}

Budiono, dkk. (2011), Rancang Bangun Urinoir yang Islami. Laporan Akhir Hibah Penelitian Strategis Nasional Tahun 2011. LPPM-ITS. Surabaya.

Shobirin, dkk. (2014), Ibadah itu Indah, Pustaka Tebuireng, PP. Tebuireng, Jombang.

Kementrian Kebudayaan dan Pariwisata. (2004). Membangun Toilet Umum dengan MudahKering itu sehat. Buklet 2 ; Gerakan Nasional Standarisasi Toilet Umum Indonesia. Jakarta. 
Budiono, Lea Kristina Anggraeni

Desain Toilet dan Tempat Wudhu Masjid 